\title{
"Nuestro Estado ha de ser un Estado católico en lo social": la familia y la Iglesia en el discurso social de los regímenes ibéricos en las décadas de 1930-1960
}

\section{"Our State has to be a Catholic State in the social sphere": family and Church in the social discourse of the Iberian regimes in the 1930s-1960s}

Pedro TEIXEIRA PEREIRA

Universidade Nova de Lisboa

\begin{abstract}
RESUMEN
Las dictaduras de Franco y Salazar compartieron varios de los instrumentos que contribuyeron a la edificación y sustentación de sus regímenes a lo largo del tiempo: la Iglesia y la Familia se convirtieron en piedras angulares de los discursos de Estado. Por debajo del manto protector del Cristianismo y apoyado sobre la familia, los dictadores ibéricos construyeron lo que denominaron política social: la familia salió reforzada en sus tareas sociales de asistencia y previsión, y la Iglesia aseguró la legitimación para la acción social que los regímenes consideraban suya. En el nuevo contexto ideológico que se estableció después de la Segunda Guerra Mundial, en el que el entorno fascista sucumbía, el discurso de los regímenes se agarraba más aún a los valores tradicionalistas para disfrazar los verdaderos colores de sus políticas sociales.
\end{abstract}

PALABRAS CLAVE

Franco; Salazar; Política social; Iglesia; Familia.

\begin{abstract}
The dictatorships of Franco and Salazar had in common several instruments that contributed to the edification and support of their regimes over time: Church and Family became the cornerstones of State discourses. Beneath the protection of the mantle of Christianity and supported upon their notions of the family, the Iberian dictators built what they called social policy: the role of family was reinforced in terms of its social tasks of assistance and welfare, and the Church ensured the legitimization of the social action that the regimes called their own. In the new ideological context that was established after the Second World War, where the fascist environment was weakening, the discourse of the regimes clung increasingly to traditionalist values to disguise the true colours of their social policies.
\end{abstract}

KEYWORDS

Franco; Salazar; Social policy; Church; Family. 
Este artículo plantea establecer similitudes entre los discursos sociales de los regímenes de Franco y Salazar en sus ejes definidores, así como su conformidad con valores tradicionales de la Iglesia Católica como eran la centralidad de la familia y de la fe en la sociedad, que buscaban como elementos legitimadores y protectores de su acción. En este contexto, y beneficiándose de la influencia y aceptación que la fe tenía en las poblaciones ibéricas, tradicionalmente católicas y con altos niveles de analfabetismo, las políticas sociales del régimen esperaban lograr la seducción de las masas para sus retos sociales y, así, implementar de una manera más profunda y generalizada su visión de sociedad, obediente a la casi sacralizada palabra del Estado. El texto recurrirá a los discursos públicos proferidos por los líderes, de facto, de los regímenes, así como a intervenciones de los responsables ministeriales y políticos del ámbito del poder. Se destacará una serie de mensajes comunes, así como su aproximación a la visión católica. A la luz de los recorridos de los regímenes de Salazar y Franco surge la construcción de un conjunto de políticas de índole social a partir de las décadas fundacionales de 1930 y $1940^{1}$ respectivamente, hasta la transformación tecnócrata de las políticas, y de los discursos, de consenso en los inicios de la década de 1960, en un marco cronológico puntuado por las reformas de 1962 en Portugal, y de 1963 en España, en las que se plantea el rumbo hacia el concepto y organización de la Seguridad Social.

Políticamente, y aunque el camino fuera muy distinto en ambos lados de la frontera, Portugal y España caminaron hacia el establecimiento y consolidación de regímenes autoritarios. Portugal evolucionó desde una dictadura militar establecida en 1926, en la que surgió António de Oliveira Salazar, hasta su conversión en dictadura personal cuando asumió la jefatura del Conselho de Ministros en 1932, ratificado por la Constituição de 1933. Mientras tanto, en España, tras los años polarizados de la Segunda República, "la primera y fallida experiencia democrática española"2, la Guerra Civil concluyó con la victoria del bando nacionalista encabezado por Francisco Franco, que había liderado el golpe de Estado frente al Gobierno republicano de izquierda y que asumirá el cargo de Jefe del Estado.

La década de 1930, aunque en diferentes momentos, señaló el comienzo de las dictaduras y de su discurso social. En una lectura global, la misma década fue, también, enmarcada por la afirmación del régimen de Hitler que fue beneficiado por la política británica de appeasement, que proporcionó espacio de maniobra para las derechas europeas con crecientes influencias fascistas ${ }^{3}$. Finalmente, el crash de 1929 y la consecuente depresión económica contribuyeron, en alguna medida, como contexto favorable a la edificación de las políticas sociales autoritarias ibéricas, aunque la fuerte recesión internacional no fue el factor decisivo en la edificación social de los Estados Nuevos, una vez que el sentir de la crisis

foi relativamente tardio (1931 é o ano em que mais claramente se fazem sentir entre nós
os efeitos da crise mundial), relativamente rápido (em 1932 a maioria dos indicadores

1. Sobre el alcance de las políticas sociales en el Franquismo véase, Carme Molinero, La Captación de las Masas. Política Social y Propaganda en el Régimen Franquista, Madrid, Cátedra, 2005.

2. Pablo Martín de SAnta Olalla Saludes, "De la dictadura a la democracia. Marcelo González, arzobispo de Toledo en tiempos de cambio”, en Carlos NAVAJAS ZUBELDIA, y Diego ITURRIAGA BARCO (eds.), Crisis, dictaduras, democracia. Actas del I Congreso Internacional de Historia de Nuestro Tiempo, Logroño, Universidad de La Rioja, 2008, p. 415.

3. Francesc Vilanova, “Múnich, Praga y los judíos como pretexto. La 'impregnation fasciste’ de las derechas catalanas ante la nueva guerra europea (1938-1939)”, História. Revista da FLUP, IV Serie, 10-1 (2020), pp. 105-129 (https://doi.org/10.21747/0871164X/hist10_1a6). 
já demonstram um início de recuperação), relativamente pouco intenso (os dados disponíveis mostram que para os diferentes domínios económicos e sociais o choque da crise esteve muito longe de atingir os níveis ou a duração da maioria dos outros países afectados) ${ }^{4}$.

Difícilmente podemos considerar las políticas sociales de los regímenes como un modelo social, dada su carencia de visión de conjunto y universalidad. Entendemos que la política social del Estado $N o v o^{5}$ y del Nuevo Estado no inaugura la política social dentro de la esfera pública en Portugal y España. Sin embargo, los edificios legislativos republicanos ibéricos (1910-1926 en Portugal, y 1931-1936/39 en España), aunque en la época ambos estuviesen impregnados de un profundo sentido de justicia social, resultaron un fracaso, por lo menos en la fase de su materialización, toda vez que la teoría no produjo obra. De esta forma, estos regímenes ibéricos fascistizados ${ }^{6}$, y el español de definición nacional-sindicalista, en cuanto democracia orgánica ${ }^{7}$ en la retórica del régimen, miran hacia el pasado más reciente de sus países y, reaccionando, concluyen que tienen que (re)construir la esfera social bajo su visión estatal y concepción nacional: "Entre o atomismo das doutrinas cem por cento individualistas $e$ a absorção da economia pelo Estado situa-se a posição que o nosso corporativismo escolheu" ${ }^{8}$. La declaración viene de Lisboa, pero también será acogida en Madrid ${ }^{9}$. Ambos regímenes mantendrán el corporativismo ${ }^{10}$, lato sensu, en la dimensión de las ideas ${ }^{11}$ que no encontrarán concretización cabal por parte de la acción política, a pesar de los mecanismos que los regímenes dedicaron a la ordenación, integración y control de los agentes sociales y económicos, patrones y trabajadores por medio de sindicatos verticales y nacionales ${ }^{12}$.

4. Fernando RosAs, “Saber Durar (1926-1949)”, en José MATTOSo (dir.), O Estado Novo (1926-1974), vol. 7 de la História de Portugal, Lisboa, Editorial Estampa, p. 126.

5. Véase Pedro TeiXeira Pereira, O Estado Novo e a Construção da sua Política Social, Porto, U. Porto Edições, 2015.

6. Luciano Aronne De Abreu y Paula Borges SANTOS, “Corporativismo e Salazarismo em perspectiva: o olhar de Fernando Rosas”, Estudos Ibero-Americanos, 42-2 (mayo-ago. 2016), pp. 553-559. Dulce FrEIRE y Nuno Estêvão FERREIRA, “Construção do sistema corporativo em Portugal (1933-1974)”, en Fátima Moura Ferreira, Francisco AzeVEdo MEndes y Jorge MANO ToRres (coords.), Organizar o país de alto a baixo: políticas de edificação corporativa no Estado Novo português, Coimbra, Tenacitas, 2016.

7. Francisco Sevillano CAlero, “El Nuevo Estado y la ilusión de la 'democracia orgánica'. El referéndum de 1947 y las elecciones municipales de 1948 en España”, Historia Contemporánea, 24, 2002, pp. 355-387.

8. Dez Anos de Política Social 1933-1943, Lisboa, INTP, 1943, p. 6.

9. Se encuentra respaldo en Pedro CARASA cuando define el Franquismo como un régimen cuyo "concepto de justicia es más corporativo que comunitario, más cooperativo que distributivo, una justicia más familiar que individual, más nacional que social” ("La revolución nacional-asistencial durante el primer Franquismo (1939-1940)”, Historia Contemporánea, 16 (1997), p. 124).

10. Francisco BERnAL GARCÍA, “Corporativismo y Fascismo. Los sistemas de relaciones laborales autoritarios en la Europa de entreguerras”, Hispania Nova, 15 (2017), pp. 45-75; Miguel Ángel PERFECTO, “Corporativismo y política social en España. Orígenes y evolución”, Estudos Históricos, vol. 31, n. 64 (mayo-agosto 2018), pp. 277-296 (https://doi.org/10.1590/s2178-14942018000200009).

11. Sergio FernÁNDEz RiQuelme, "Sociología, Corporativismo y Política Social en España. Las décadas de pensamiento corporativo en España: de Ramiro de Maeztu a Gonzalo Fernández de la Mora [18771977]”, tesis doctoral, Universidad de Murcia, 2008.

12. Glicerio SÁNCHEZ RECIO, “El sindicato vertical como instrumento político y económico del régimen franquista”, Pasado y Memoria, 1 (2002), pp. 19-32, (https://doi.org/10.14198/PASADO2002.1.01). 
Además, desde el punto de vista orgánico, ambos regímenes establecieron órganos corporativistas, como es el caso de las Cortes en España ${ }^{13}$, y de la Câmara Corporativa $^{14}$ en Portugal. Así, el corporativismo se inscribe en las matrices ideológicas del fascismo así como en el de la acción política católica: “o processo de engenharia política, através do qual essas ditaduras forneceram um canal para a cooptação de interesses organizados e seu discurso legitimador, tornou-se um modelo da década de $1930 " 15$.

\section{Hablando de la familia...}

De acuerdo con el ideario de los regímenes, uno de los actores principales y sustentadores de las políticas sociales ibéricas sería la familia. El prisma de análisis del artículo es el de Estado, de la res publica. El ideario salazarista entiende el Estado como una entidad sacralizada, como un pater de un pueblo que, a los ojos del régimen, no tiene rumbo definido. Sin embargo, en lo que a cuestiones sociales se refiere, es otro el organismo que ostenta la primacía de la acción y de la moralidad. Hablamos de la familia.

Por ser uma instituição natural, ela é também uma instituição social, e eminentemente social, pois nenhuma outra pode reclamar-se de maior importância e influência na vida do homem. Dela nasceu o Estado, que historicamente foi um desdobramento de famílias ${ }^{16}$.

El Estado salazarista es, por lo tanto, moralmente respetuoso con la institución familiar y tiene un interés concreto en ella, ya que, como vimos y continuaremos observando, es en la familia donde, para el régimen, debe residir la primera y principal institución de previsión para aminorar los problemas sociales:

temos como lógico na vida social como útil à economia a existência regular da família do trabalhador; temos como fundamental que seja o trabalhador que a sustente; defendemos que o trabalho da mulher casada e geralmente até o da mulher solteira, integrada na família e sem responsabilidade da mesma, não deve ser fomentado: nunca houve nenhuma boa dona de casa que não tivesse imenso que fazer ${ }^{17}$.

Así, se postula que:

Não discutimos a família. Aí nasce o homem, aí se educam as gerações, aí se forma o pequeno mundo de afectos sem os quais o homem dificilmente pode viver. Quando a

13. Martí MARíN, "La democracia orgánica como forma de representación política: un análisis de las fórmulas de cooptación de procuradores en Cortes y de sus resultados”, Estudos do Século XX, 16 (2016). La constitución de las Cortes pretendió señalar, a través de la elegibilidad de sus miembros, a una construcción creciente del corporativismo al "dibujar una historia de exitoso reformismo que habría llevado a un parlamento cada vez más representativo, dentro de su especificidad corporativa, a medida que el dictador cedía en su empeño intervencionista y dejaba espacio a las instituciones” (p. 99).

14. Nuno Estêvão Figueiredo Miranda Ferreira, A Câmara Corporativa no Estado Novo: Composição, Funcionamento e Influência, Lisboa, ICS/UL, 2009.

15. António Costa Pinto, “Corporativismo e ditaduras: o Salazarismo e o Franquismo”, en Luciana Murari, Tatyana DE AmAral Maia y Antonio DE Ruggiero (orgs.), Do Estado à Nação: política e cultura nos regimes ditatoriais dos anos 1930, Porto Alegre, ediPUCRS, 2018, p. 217.

16. Manuel Rodrigues, "Igualdades e Desigualdades”, en Problemas Sociais (Questões Políticas), Lisboa, Ed. Ática, 1943, p. 118.

17. António DE Oliveira SAlazAR, “Conceitos económicos da nova Constituição” (16-3-1933), Discursos. 1928-1934, vol. I, Coimbra, Coimbra Editora, Lda., 1935, p. 201. 
família se desfaz, desfaz-se a casa, desfaz-se o lar, desatam-se os laços de parentesco, para ficarem os homens diante do Estado isolados, estranhos, sem arrimo e despidos moralmente de mais de metade de si mesmos; perde-se um nome, adquire-se um número - a vida social toma logo uma feição diferente ${ }^{18}$.

En palabras de Manuel de Lucena, a propósito de la ideología corporativa, a família, à qual a doutrina salazarista reconhece uma importância primordial. Célulamãe da organização social, a família no se limita a produzir cidadãos. Gera crentes: o próprio Cristo veio de Maria e José. A Família tem portanto direitos intocáveis, uma autonomia de que também gozam, em grau diverso, todos os corpos sociais intermédios, dos municípios às Corporações ${ }^{19}$.

De igual modo, para la doctrina nacional-sindicalista de España la familia ocupa el núcleo de la sociedad. Así, toda la nueva concepción de política social brotaba y gravitaba en torno a la unidad familiar. Afirma Franco que, "Para nosotros la familia constituye la piedra básica de la Nación” ${ }^{20}$. La familia es vista como el "objetivo inicial de reconstrucción social”21, y de su desestructuración resultarían las causas de la mayoría de los males sociales de mediados del siglo XX. En este contexto se sitúa una relevante lectura sociológica aducida por Moisés de Lemos Martins sobre el régimen portugués de las consciencias de los hombres y mujeres, que se esperaban que fueran expurgados de ideas que podrían tornarse peligrosas para el funcionamiento de la sociedad $^{22}$. En cuanto a la centralidad de la familia como primer instrumento de apoyo social, el paralelo entre Franco y Salazar no podría ser más exacto:

Eis na base a família -célula social irredutível, núcleo originário da freguesia, do município e, portanto, da Nação: é, por natureza, o primeiro dos elementos políticos orgânicos do Estado constitucional. [...] Em suma: pretende-se construir o Estado social e corporativo em estreita correspondência com a constituição natural da sociedade. As famílias, as freguesias, os municípios, as corporações onde se encontram todos os cidadãos, com suas liberdades jurídicas fundamentais, são os organismos componentes da Nação, e devem ter, como tais, intervenção directa na constituïção dos corpos supremos do Estado: eis uma expressão, mais fiel que qualquer outra, do sistema representativo ${ }^{23}$.

18. “As grandes certezas da Revolução Nacional”, ibídem, vol. II, pp. 133-134.

19 Manuel de LUCENA, “A evolução do sistema corporativo portugués”, O Salazarismo, vol. I, Lisboa, Perspectivas \& Realidades, 1976, p. 51. Vamos a permitirnos disentir del uso del término cidadãos puesto que, realmente, no era ese el propósito y la visión del Estado Novo. Efectivamente, la familia está guiada hacia el modelo de organización corporativa: "na família, por exemplo, que não entra na organização corporativa 'stricto sensu', encontramos a mesma recusa dos conflitos e o mesmo princípio de acção: mestre, o pai colabora harmoniosamente com os fillhos-aprendizes. E a mulher-mãe é como o companheiro subalterno dos antigos mestres. Quando este espírito domina a sociedade inteira -e nomeadamente as relações entre as classes e grupos sociais- o corporativismo vigora, qualquer que seja a forma assumida" (ibídem, p. 99).

20. Francisco Franco, “Mensaje de fin de año” (31-12-1953), en Pensamiento Político de un General: Franco, vol. III, Vigo, C. P. Editor, 1995, p. 747.

21. 25 Años de Política Social, Madrid, Delegación Nacional de Organizaciones del Movimiento, 1961, p. 7. Ya desde los años 1940, voces autorizadas afirmaban que, "Para nosotros, la cuestión es clara. Debe ser la familia el sujeto de la seguridad social” (Luis BuRGOS, “La Familia y la Seguridad Social”, Revista de Estudios Políticos, suplemento de Política Social, 2 (1945), p. 84).

22. Moisés DE LEMOS MARTINS, "Uma solidão necessária à ordem salazarista: a família como terapêutica nacional”, Cadernos de Ciências Sociais, (abril 1986), p. 79.

23. SALAZAR, “Princípios fundamentais da revolução política” (30-7-1930), Discursos, vol. I, pp. 85 y 87. 
Doce años después de esta declaración, proclamada en un momento en que Salazar todavía era ministro de Finanzas y no presidente del Consejo de Ministros, se recuerdan las bases de apoyo social en Portugal y, en orden decreciente, de rapidez e importancia: “A família é o primeiro grupo natural, a profissão outro, a Igreja outro, a sociedade civil outro" 24 .

Ambos regímenes insisten en subrayar el papel principal de la familia, o sea, de los particulares, en cuanto a su deber social. Por lo tanto, independientemente de la construcción de toda la malla de protección social que viene a ser edificada teniendo como base la previsión gestionada por el Estado y en la asistencia proporcionada por el Estado, para los regímenes autoritarios ibéricos el organismo financiador y asegurador del apoyo social por excelencia era la familia ${ }^{25}$. Esta constituye la primera línea de combate contra la necesidad social. Para comprobarlo, y como ya referimos, se puede acudir a múltiples referencias a la misma y a las virtudes y obligaciones de la familia como órgano corporativo, como la primera de las corporaciones en un régimen corporativo. Para el caso español, en el que "el Franquismo crea un régimen asistencial totalitario"26, desde 1938 el Fuero del Trabajo consagra a la familia como “célula primaria natural y fundamento de la sociedad, y al mismo tiempo como institución moral dotada de derecho inalienable y superior a toda ley positiva”27, señalando el vínculo con los valores de la Iglesia.

Efectivamente, el campo semántico de la política social franquista confiere una gran centralidad a nociones como la familia y su unidad. Incluso se afirma que, "Para la política laboral española la unidad no es el trabajador, sino el trabajador con su familia”, como proclamó José Antonio Girón de Velasco, el ministro de Trabajo del régimen hasta $1957^{28}$. Sin embargo, en el ideario franquista, que hace del ideal del conjunto, de la corporación, el latir de la sociedad, la noción de familia no se circunscribe a los lazos sanguíneos, supera la dimensión del hogar familiar o se trasplanta incluso hasta otra realidad, la del trabajo:

24. Ibídem (23-7-1942), “O Corporativismo e os trabalhadores. Resposta do Presidente do Conselho à mensagem dos dirigentes sindicais.”, Discursos, vol. III, p. 357.

25. Véase, Ana M. GuilléN, “Un siglo de previsión social en España”, Ayer, n. ${ }^{o} 25$ (1997), pp. 151-178.

26. Pedro CARASA, "Lo Privado y lo Público en el Sistema Asistencial: El Triángulo Iglesia Ayuntamiento - Estado en la Beneficencia Española”, en Laurinda ABrEu (ed.), Asistencia y Caridad como Estrategias de Intervención Social: Iglesia, Estado y Comunidad (siglos XV-XX), Bilbao, Universidad del País Vasco, 2007, p. 163.

27. "Fuero del Trabajo, decreto de 9 de marzo de 1938”, en Leyes Fundamentales del Estado Español, Madrid, Editorial Goñi, 1964, pp. 15-16. El posterior Fuero de los Españoles refuerza igualmente el valor de la familia para el Nuevo Estado, al declarar que "el Estado reconoce y ampara a la familia como institución natural y fundamento de la sociedad con derechos y deberes anteriores a toda Ley humana positiva”. "Fuero de los Españoles, Ley de la Jefatura del Estado de 17 de julio de 1945”, Capítulo Segundo, art. 22. ${ }^{\circ}$, en Ibídem, p. 6. Es notoria la proximidad en las definiciones que ambas normas presentan.

28. José Antonio GIRÓN, Quince Años de Política Social dirigida por Francisco Franco (discurso de apertura del I Congreso Iberoamericano de Seguridad Social, el día 22 de mayo de 1951), Madrid, Ediciones O. I. D., 1951, p. 16. Sobre GIRÓN, véase Pedro GONZÁLEZ MuRILlO, “La política social franquista: el Ministerio de José Antonio Girón de Velasco (1941-1957)”, tesis doctoral, Universidad Complutense de Madrid, 1998, pp. 13-24. Sobre el Ministerio de Trabajo en España, ídem, "El Ministerio de Trabajo, 1939-1957: de la trinchera al franquismo social”, en Santiago CASTILlo (dir.), Centenario del Ministerio de Trabajo 1920-2020, Madrid, Ministerio de Trabajo y Economía Social, 2020, pp. 133-159. 
La familia no acaba en el hogar, que hay otra nueva familia: la de la profesión, creada y unida por los lazos y vínculos nacidos de la convivencia en el trabajo; la familia de la ayuda, del socorro, de la no indiferencia ante los males de nuestros hermanos y de nuestros compañeros y camaradas en el trabajo ${ }^{29}$.

Franco completará su explicación dando cuenta de que la familia se constituye en un microcosmos representativo de la sociedad española: "Sé que en cada familia se reproducen en pequeño la complejidad y las dificultades del país entero, cuyo bien común es el cometido del Estado”30.

\section{Hablando de la Iglesia...}

Analizando la posición y la influencia de la institución religiosa sobre la cuestión social, ésta impregnará claramente las políticas sociales ibéricas de Salazar y Franco. Si afirmamos que el despuntar de los actos caritativos en Europa fue motivado por la cultura cristiana, de igual modo este momento de transformación de los modelos de protección social europeos fue alentado por una evolución del discurso del Vaticano. En relación a esta materia, la reacción primera, impulsora y definidora de la Santa Sede en el dominio de lo social, ocurre a través de la encíclica de León XIII, Rerum Novarum (15-05-1891), donde se argumenta a favor a la integridad y respetabilidad del proletariado, se defiende la previsión libre, es decir, el ahorro y el derecho de los obreros a constituir asociaciones de socorro mutuo para evitar posibles infortunios, como los sindicatos -preferentemente de carácter católico-, en forma de corporaciones para reivindicar justicia en las condiciones del trabajo. Este escrito preconiza, por tanto, la evolución de un paternalismo social hacia un modelo de bienestar generalizado. A pesar del carácter progresista de la encíclica, ya que defiende la dignidad de la clase obrera frente a la explotación patronal ${ }^{31}$, asume como punto de partida para la reflexión social propuesta por la Iglesia "en primer lugar, que debe ser respetada la condición humana, que no se puede igualar en la sociedad civil lo alto con lo bajo”. Así, el ímpetu de reformismo social en Rerum Novarum se manifiesta, parcialmente contaminado con la idea de pasividad, o prácticamente, de resignación social por parte del individuo de las clases sociales inferiores por sus malas condiciones de vida.

La idea de que el individuo debe ser activo para garantizar su propia subsistencia está bien presente en la visión social de las dictaduras ibéricas. De nuevo en la Rerum Novarum se ubica una noción que se constituirá en uno de los pilares de la comprensión de lo social de los estados fascistas europeos:

\footnotetext{
Y no hay por qué inmiscuir la providencia de la república, pues que el hombre es anterior a ella, y consiguientemente debió tener por naturaleza, antes de que se constituyera comunidad política alguna, el derecho de velar por su vida y por su cuerpo [...]. He aquí, pues, la familia [...] la cual es de absoluta necesidad que tenga unos derechos y unos deberes propios, totalmente independientes de la potestad civil.
}

29. Francisco FrAnCo, “A la Junta de Gobierno de la Asociación General de Empleados y Obreros de los Ferrocarriles de España” (25-2-1947), Franco ha Dicho, vol. I, Madrid, Ediciones Voz, 1947, p. 130.

30. Francisco Franco, “Mensaje de fin de año” (31-12-1954), en Discursos y Mensajes del Jefe del Estado. 1951-1954, Madrid, Publicaciones Españolas, 1955, p. 547.

31. "Si la clase patronal oprime a los obreros con cargas injustas o los veja imponiéndoles condiciones ofensivas para la persona y dignidad humanas; si daña la salud con trabajo excesivo, impropio del sexo o de la edad” (LEÓN XIII, Rerum Novarum, consultable en https://www.vatican.va/content/leoxiii/es/encyclicals/documents/hf_l-xiii_enc_15051891_rerum-novarum.html). 
La única excepción a esta disposición se verifica en el caso de la categoría social de los indigentes, ante la cual el Estado, "éste deberá, por consiguiente, rodear de singulares cuidados y providencia a los asalariados, que se cuentan entre la muchedumbre desvalida”. Será en esta fundamentación doctrinal católica, claramente opuesta a las ideas socialistas que se afirmaban desde finales del siglo XIX, en la que se apoyara que el discurso social de los Estados Nuevos en cuanto a su posición de cara a las necesidades sociales: "El fascismo, o corporativismo de Estado, tomará sus raíces corporativistas tanto de la visión organicista como de la visión cristiana de la sociedad" ${ }^{32}$.

A lo largo de 1930, se asiste a una evolución en la posición de la Iglesia Católica sobre esta materia. El Papa Pio XI, en su encíclica Divini Redemptoris (1937), refuerza la importancia de la institución de seguros públicos, es decir, de seguros sociales, para promocionar la justicia social en las categorías más desfavorecidas, encuadradas en una lógica de combate fiel al ideario comunista que entonces se afirma en Europa:

El comunismo de hoy [...] encierra [...]. Un seudo ideal de justicia, de igualdad y de fraternidad en el trabajo, satura toda su doctrina y toda su actividad con un cierto misticismo falso, que a las masas halagadas por falaces promesas comunica un ímpetu y tu entusiasmo contagiosos ${ }^{33}$.

De este modo, queda patente una nueva afinidad entre la doctrina católica y los regímenes salazarista y franquista en su construcción, tres partes ferozmente anticomunistas. Sin embargo, no se agotan aquí las similitudes de pensamiento entre los Estados ibéricos y el Vaticano. En la misma encíclica, el Papa afirma: "hay que lograr la verdadera prosperidad de los pueblos por medio de un sano corporativismo" 34 , lo que conecta casi orgánicamente con el ideario y la acción del Estado Novo y el Nuevo Estado en el campo social, pautados por esta fuerte influencia y respaldo doctrinal de Roma.

Si, de acuerdo con la ideología de los regímenes, la familia ocupa el lugar principal en el apoyo social a los individuos, le sigue de inmediato el auxilio religioso y no solo- prestado por la Iglesia Católica, muy presente y próxima al poder dictatorial de Salazar y de Franco. En el caso del Estado salazarista, aun definiendo el encuadramiento doctrinario en el que el nuevo régimen iba a estructurar su modelo de protección social, se refuerza la cada vez más estrecha relación entre la concepción social salazarista y la doctrina social del Vaticano, que

já tinha recuperado muito do terreno perdido na travessia dos regimes liberal e republicano [...]. A Igreja pretende criar uma alternativa à estratégia laicista, retomando os seus privilégios e assumindo um papel preponderante na visão do Mundo. O Estado Novo, tratando-se dum Estado Corporativista e assente em princípios

32. Josep PICÓ, Teorías sobre el Estado del Bienestar, 3. ${ }^{a}$ ed., Madrid, Siglo XXI de España Editores, 1999, p. 69.

33 PIO XI, Divini Redemptoris, consultable en https:/www.vatican.va/content/piusxi/es/encyclicals/documents/hf_p-xi_enc_19370319_divini-redemptoris.html.

34. Ibídem. 
da doutrina social da Igreja, não só apoiará essa estratégia da Igreja como a fará sua ${ }^{35}$.

Hemos verificado que la política social del Estado Novo se presentaría como cercana al magisterio social del catolicismo y a las orientaciones emanadas de la Santa Sede, con lo que nuestra interpretación apuesta por un perfil integrista ${ }^{36}$. Sin embargo, importa aclarar que las relaciones institucionales entre el poder político y el poder religioso no estuvieron exentas de tensiones, de distanciamientos e incluso de alguna procura búsqueda de emancipación de los propios retos de la institución religiosa de cara a la situación política, particularmente a partir de 1945, como relevantemente señala Paula Borges Santos ${ }^{37}$.

\section{En 1937, Pio XI declaraba que}

Pero no se cumplirán suficientemente las exigencias de la justicia social si los obreros no tienen asegurado su propio sustento y el de sus familias con un salario proporcionado a esta doble condición; si no se les facilita la ocasión de adquirir un modesto patrimonio que evite así la plaga del actual pauperismo universal; si no se toman, finalmente, precauciones acertadas en su favor, por medio de los seguros públicos o privados, para el tiempo de la vejez, de la enfermedad o del paro forzoso ${ }^{38}$.

Aquí, el Estado Novo cumple con el Vaticano a través de la previsión social que edifica en estos años. También la Iglesia se beneficia, aunque no de la misma manera ${ }^{39}$, de esta unión Trono-Altar, pues el régimen salazarista propicia "o enquadramento simbólico/ideológico de largos sectores da sociedade, particularmente aqueles mais próximos da sociedade rural tradicional e abriu-lhe espaço social para as suas organizações próprias" ${ }^{40}$. Pragmáticamente, exime a la institución religiosa de

35. Alcina MARtins, Génese, Emergência e Institucionalização do Serviço Social, Lisboa, F.C.G. 1999, p. 7; Véase, Manuel Braga DA CRUZ, O Estado Novo e a Igreja Católica, Lisboa, Editorial Bizâncio, 1998, p. 18. A este respecto, véase también Fernando ROSAS, Salazar e o Poder. A Arte de Saber Durar, Lisboa, Tinta-da-China, 2012, pp. 257-280, en especial el capítulo titulado “A cumplicidade da Igreja católica: um neo-regalismo funcional”.

36. Se registra, igualmente, la existencia de una posición minimalista, en autores como Augusto Moraes Sarmento, que consideraban que la organización corporativista del Estado Novo se alejaba de la doctrina social de la Iglesia, en la medida en que ésta abogaba porque las organizaciones corporativas deberían ser autónomas de la intervención del Estado, lo que no se verificaba en Portugal (Manuel PINHO DE FERreirA, A Igreja e o Estado Novo na obra de D. António Ferreira Gomes, Porto, Fundação SPES/Universidade Católica Portuguesa, 2004, pp. 305-311).

37. Paula Borges Santos, A Segunda Separação. A Política Religiosa do Estado Novo (1933-1974), Coimbra, Almedina, 2016, pp. 20-23.

\section{Divini Redemptoris.}

39. Por ejemplo, la Iglesia portuguesa no recuperó mucho del patrimonio estatalizado durante la Primeira República.

40. António Costa PINTO, "O Estado Novo português e a vaga autoritária dos anos 1930 do século XX”, en ídem y Francisco Carlos Palomanes Martinho (orgs.), O Corporativismo em Português. Estado, Política e Sociedade no Salazarismo e no Varguismo, Lisboa, ICS, 2008, p. 41. El francés Jacques GEORGEL veía las relaciones Estado-Iglesia del siguiente modo: “a Igreja não tinha razões para estar descontente [...] Ditadura indirectamente clerical, pretendendo realizar no corporativismo a doutrina social da Igreja, o salazarismo sabia bem quanto devia ao clero" (O Salazarismo, Lisboa, Dom Quixote, 1985, p. 197). Sin embargo, y sin perder la perspectiva, atendiendo a la estructura y no a las diversas conjeturas, "Mesmo que se considere que, por 'razão de Deus e "razão de Estado"', havia uma confluência entre os dois pólos, Estado e Igreja, jamais Salazar e Marcello Caetano desejaram semelhante confusão” (Luís ReIS TORGAL, Estados Novos. Estado Novo. Ensaios de História Política e Cultural, vol. 1, Coimbra, Imprensa da Universidade de Coimbra, 2009, p. 427). 
impuestos y le devuelve la ilegalización del divorcio. De este modo, el Estado Novo ofrece a la Iglesia la posibilidad de que se concrete la recristianización de Portugal. El Concordato de $1940^{41}$ viene a ratificar lo que la praxis de los últimos años demostraba, al formalizar el vínculo de colaboración entre el Estado Novo y la Iglesia ${ }^{42}$. Además, su propósito, consagrado en el texto, era "regular, por mútuo acordo e de modo estável, a situação jurídica da Igreja Católica em Portugal, para a paz e maior bem da Igreja e do Estado" ${ }^{3}$. Ahora bien, si partimos de la premisa arriba referida, y con la cual concordamos, se puede hacer otra lectura de Fernando Rosas, que explica el contenido de la acción de la Iglesia mientras era instrumentalizada por el Estado Novo: "um elemento de sujeição e obscurantismo das massas, cujos sentimentos religiosos são explorados para manter uma ordem política assente na estagnação parasitária, na exploração e na opressão" 44 .

El Estado Novo no se asume formalmente como católico o confesional, aunque en la práctica política encontremos ejemplos que apuntan en sentido contrario, el de una progresiva dimensión teocrática, como la casi absoluta tutela de la educación por parte de la Iglesia -en la metrópoli y en las colonias/provincias ultramarinas-, además de que, a partir de su reforma de 1951, la Constituição portuguesa instituyó la fe católica como la oficial en la Nación ${ }^{45}$. En este contexto, las relaciones entre el Estado Novo y la Iglesia Católica ${ }^{46}$ se inician en un clima favorable, de colaboración, pero al llegar al período post-Segunda Guerra Mundial y en particular a la década de $1950^{47}$, encontraremos señales y posturas por parte de algunos elementos de la estructura eclesiástica desfavorables al régimen, como será el caso del cura y diputado en la Assembleia Nacional Abel Varzim ${ }^{48}$, pero sobre todo la notoria posición del obispo de Oporto, D. António Ferreira Gomes que, por culpa de un texto publicado, abiertamente hostil al salazarismo, conocerá un exilio forzado durante más de una década. El régimen, además en ambos Estados Nuevos, utiliza la Iglesia como manto protector y sobre todo como parte legitimadora de su existencia y acción, lo que más se hace sentir en las zonas menos letradas y más ligadas a la voz de la Iglesia, en el interior, en el

41. Sobre esta temática, véase Rita Almeida de CARVAlHo, A Concordata de Salazar, Lisboa, Temas e Debates, 2013; Duncan SiMPSON, A Igreja Católica e o Estado Novo Salazarista, Lisboa, Ed. 70, 2014.

42. Cabe destacar que, al igual que el Franquismo, el régimen portugués, de acuerdo con el artículo X del Concordato de 1940, ostentaba el derecho de objetar las nominaciones para arzobispo y obispo en el país, lo que conllevaba un ascendente del poder político sobre la jerarquía católica portuguesa.

43. “Concordata entre a Santa Sé e a República Portuguesa”, en Colecção oficial de legislação portuguesa, año 1940, II sem., 1954, p. 26.

44. Fernando RosAs, “A Igreja em Portugal nos anos 40”, História, n. 46 (1982), p. 5.

45. Manuel Loff, “Los regímenes autoritarios”, Ayer, 37 (2000), p. 134; RosAs, Salazar e o Poder, p. 257.

46. Véase Maria Inácia RezolA, “A Igreja Católica nas origens do salazarismo”, Locus: revista de história, 18-1 (2012), pp. 69-88.

47. "Esta consciência social crescentemente crítica [...] alimentava-se na Doutrina Social da Igreja que as Semanas Sociais Católicas vão difundindo insistentemente a partir de 1940” (CRUZ, O Estado Novo, p. 96). La Primera, subordinada al tema "Aspectos Fundamentais da Doutrina Social Cristã", junio de 1940; la Segunda, sobre las "Bases Cristãs duma Ordem Nova”, marzo de 1943; la Terceira, que trató “O Problema do Trabalho”, en 1949, y la Cuarta, sobre “O Problema da Educação”, en octubre de 1952.

48. Sobre los discursos en torno de la cuestión religiosa véase, Paula Borges SANTOS, A Questão Religiosa no Parlamento, volume III (1935-1974), Lisboa, Assembleia da República, 2011. Para un análysis sociológico de la prática discursiva salazarista relativamente a la Iglesia véase, Moisés DE LEMOS

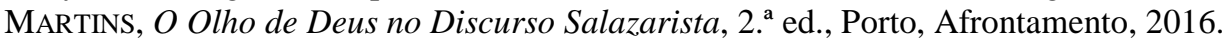


espacio rural ${ }^{49}$, en el país mayoritariamente analfabeto ${ }^{50}$ : "o regime conta com este sustentáculo precioso [la Iglesia] para manter as províncias rurais de Portugal numa ordem que é apresentada como imutável e que assume uma forma de infantilismo político" ${ }^{51}$. En realidad, la Iglesia portuguesa no vive en verdadero régimen confesional, sino "catolaico" en palabras de Manuel Braga da Cruz"52, por lo que no se beneficia de la misma promoción que se verifica en España, visto que, en el Nuevo Estado vecino, la unión de los dos poderes es evidente desde muy pronto, pese a que Franco afirme lo contrario.

Evaluemos entonces la posición franquista, aunque por la voz del Estado, ante este otro agente social, que siempre había desempeñado una acción notoria en el campo del apoyo social y que pasará a ser colaborador de los esquemas de protección social, la Iglesia Católica española ${ }^{53}$. Empecemos por la negación. Pese a que las siguientes declaraciones de Franco y de Girón digan. Para el primero:

\section{El Estado, sin ser confesional, concordará con la Iglesia católica, respetando la tradición nacional y el sentimiento religioso de la inmensa mayoría de los españoles, sin que ello signifique intromisión ni reste libertad para la dirección de las funciones específicas del Estado $^{54}$.}

Para Girón, "toda intervención activa de la religión en la política, de la Iglesia en el Estado, es perjudicial para los dos”

La característica social del Movimiento que sustenta el Franquismo y la consecuente legislación del régimen estableció un acercamiento a la visión católica de lo social. Además, importa notar que el clima y modus operandi profundamente anticlericales de ambos regímenes republicanos ibéricos funcionaron como tapón y simultáneamente acicate para que la Iglesia, tan pronto como fuera posible, intentara recuperar su preponderancia en los encuadramientos sociales de las poblaciones, así como en los rumbos de los Estados rescatando privilegios ancestrales, una financiación pública y el control de la educación nacional en ambos países ibéricos ${ }^{56}$. Los regímenes de Salazar y de Franco serán la solución... que concretaría la noción de un fascismo

49. También aquí si radicaba el ideal de familia para la España franquista, el núcleo campesino y, por lo tanto, el más cerca de los valores tradicionales que si intentaban reforzar. Cf. GonZÁLEz MuRILLO, "La política social franquista”, p. 174.

50. “a factura apresentada à Igreja Católica em Portugal pela concessão da Concordata, consistiu no seguinte: em continuidade histórica com o passado, a Igreja em Portugal era reclamada como zeladora e promotora da unidade nacional, [...] zeladora da fé católica com dimensão patriótica” (FERREIRA, A Igreja e o Estado Novo, p. 184).

51. Yves LÉOnARD, Salazarismo e Fascismo, Mem Martins, Editorial Inquérito, 1998, p. 111.

52. CRuz, O Estado Novo, p. 15.

53. Entre otros, véase: Julián CASAnOva, La Iglesia de Franco, Barcelona, Crítica, 2005; José Ángel TEllo, Ideología y política. La Iglesia Católica española (1936-1959), Zaragoza, Pórtico, 1984; W. J. CALlahAn, La Iglesia Católica en España (1875-1998), Barcelona, Crítica, 2002.

54. Francisco FrAnCo (1-10-1936) cit. por José ANDRÉS-GALLEGo y Antón M. PAZOS, La Iglesia en la España contemporánea, vol. II 1936-1998, Madrid, Ediciones Encuentro, 1999, p. 40.

55. José Antonio GIRÓn, Lección del Excmo. Sr. Ministro de Trabajo Camarada José Antonio Girón a los trabajadores de la Escuela de Capacitación Nacional-Sindicalista, s./l., s./ed., 1942 (18-12-1942), p. 41.

56. Manuel Loff, “O Nosso Século é Fascista!”, O Mundo visto por Salazar e Franco (1936-1945), Porto, Campo das Letras, 2008, pp. 164-165. 
genérico -para aquellos que aceptan que haya existido semejante dimensión-, particularmente en la noción patentada por Colloti de "fascismo católico"57.

Ubicando los regímenes ibéricos bajo el entendimiento de fascistizados, acompañamos a Ismael Saz en lo que consideramos una interpretación más ajustada y suficientemente inclusiva de las diferentes matices e influencias del franquismo, donde el ideario del fascismo se articula con el del nacionalismo y el de la Iglesia católica ${ }^{58}$. Eso permite afirmar que este acercamiento del Estado de Franco, así como el de Salazar, a la Iglesia se constituye en una de las estrategias para controlar uno de los instrumentos más influyentes de las sociedades de la época, el poder de la palabra del religioso ${ }^{59}$. Además, pocas formas más eficaces existirán en la época de lograr una legitimación y aceptación de ambas poblaciones frente a los regímenes dictatoriales ibéricos. Nuevas intervenciones de Franco insisten en alinear su régimen con el pensamiento social católico y aprovecharse de él, sin dejar escapar este argumento de validación:

cuando el Estado tiene un sentido social cristiano, católico y con su Magistratura y sus leyes está dispuesto a ser el fiel de la balanza y a servir a la Justicia con las realizaciones sociales para bien de la Nación y en beneficio de todos los españoles, hay que tener espíritu de colaboración” 60 .

Vislumbramos en estas palabras la imposición de una transacción, un mensaje político, una exigencia por parte del poder franquista ante la Iglesia católica española y

\section{Enzo Colloti, Fascismo, fascismi, Florencia, RCS Sansoni Editore, 1989.}

58. Ismael SAZ, "Las culturas de los nacionalismos franquistas”, Ayer, 71, (2008), p. 155 y ss. Para un análisis comparativo de la interpretación de, justamente, Ismael Saz, Alfonso Botti y Gonzalo Redondo sobre la naturaleza del régimen de Franco, véase Jesús M. ZARATIEGUi LABIANO y Alberto GARCÍA VELASCO, "Franquismo: ¿fascista, nacional católico, tradicionalista?”, en Carlos NAVAJAS ZuBELDIA y Diego ItUrRiAgA BARCo (eds.), Siglo: Actas del V Congreso Internacional de Historia de Nuestro Tiempo, Logroño, Universidad de La Rioja, 2016, pp. 379-395. La caracterización de la naturaleza ideológica del Franquismo es, como resulta evidente, muy diversa, con interpretaciones que lo ubican en la familia de los fascismos europeos (Carme Molinero y Pere YsÀs, El règim franquista. Feixisme, modernització i consens, Vic, Eumo, 2003) hasta el entendimiento de que el régimen español se debe incluir en el lato grupo de regímenes autoritarios (Juan Carlos JiMÉNEZ, Franco y Salazar. La respuesta dictatorial a los desafíos de un mundo en cambio, 1936-1968, Madrid, Sílex, 2019; entre otros) o tradicionalistas de derecha (Gonzalo Redondo, Política, cultura y sociedad en la España de Franco: 1939-1975, Vol. I, La configuración del Estado español, nacional y católico (1939-1946), Vol. II, Los intentos de las minorías dirigentes de modernizar el Estado tradicional español (1947-1956), Pamplona, Ediciones Universidad de Navarra, 1999/2005). Para una perspectiva sobre el debate historiográfico, véase, entre otros, Glicerio SÁNCHEZ RECIO, "Líneas de investigación y debate historiográfico”, Ayer, 33, 1999, pp. 17-40; Miguel Ángel GIMÉNEZ MARTínEZ, "El corpus ideológico del franquismo: principios originarios y elementos de renovación”, Estudios Internacionales, 180 (2015), pp. 11-45 (https://doi.org/10.5354/0719-3769.2015.36430).

59. En cuanto al debate sobre la(s) identidad(es) del Salazarismo, la cuestión, tal como en lo que respecta al Franquismo, tiene puntos de discordia, el que motiva discusiones académicas relevantes y polarizadas, como la de Manuel Loff y Rui Ramos, es decir, entre la visión que acerca el Estado Novo a los fascismos en una realidad política fascistizada vs. el juicio más cercano a un régimen autoritario de tipo conservador, respectivamente. Compartiendo la interpretación del Salazarismo como una dictadura de derecha tradicional, podemos leer a otros autores como António Costa Pinto, Manuel Braga da Cruz, Filipe Ribeiro de Menezes, Stanley Payne, entre otros; en campo opuesto, se perfilan Fernando Rosas, Manuel de Lucena, Luís Reis Torgal, Manuel Villaverde Cabral, entre otros (obras referenciadas en la bibliografía). Para un estudio comparativo sobre de las dictaduras ibéricas, véase Manuel LOFF, “Salazarismo e Franquismo: Projecto, Adaptação e História”, Revista de História das Ideias, 31 (2010), pp. 449-498 (https://doi.org/10.14195/2183-8925_31_17).

60. Francisco Franco, "Palabras en Sevilla”, Pensamiento Católico (13-10-1948), Madrid, Centro de Estudios Sindicales, 1958, p. 100. La cursiva es nuestra. 
sus fieles: una vez que el Nuevo Estado eleva la fe católica a la categoría oficial, se espera que la estructura eclesiástica cumpla su parte, es decir, que fidelice y mantenga adictos al mayor número posible de españoles a la doble causa político-religiosa franquista. Clarifiquemos nuestra interpretación: el discurso político-social franquista es idealizado, construido, transmitido y publicitado por la facción falangista del régimen. Éste, a su vez, instrumentaliza y se apropia de parte del discurso social católico, muy particularmente después de $1945^{61}$, en un tiempo de nuevo ordenamiento internacional en el que el Franquismo necesita urgentemente lograr una aceptación para sobrevivir. De este modo, el estilo discursivo de la posguerra se adapta para resaltar la componente católica de su acción, especialmente hasta la década de 1960, mientras el régimen busca un mecanismo encubridor de las efectivas intenciones, o falta de ellas, de avance social de los españoles. Ilustrando esta lectura, se señalan los siguientes discursos de Franco, producidos al final de la década de 1940:

De esa amplia concepción de lo socialcristiano han nacido nuestras leyes sociales, seguras en lo doctrinal, como inspiradas en las encíclicas pontificias, y eficaces en la práctica, como vienen demostrando diez años de gobierno ${ }^{62}$.

Culminando la multitud de elogios y de reciprocidades entre Franquismo e Iglesia, el Caudillo declara:

Por ser religiosos, nos sentimos profundamente sociales. Y haríamos un triste servicio a la Religión si nos despreocupáramos del interés prevalente que los problemas sociales imponen al hombre moderno ${ }^{63}$.

Girón completa y clarifica su visión sobre el binomio social Estado-Iglesia:

Como católicos y españoles siempre hemos deseado la colaboración de la Iglesia en nuestra empresa social. [...] la Iglesia y el Estado de Franco, marchando independientes por las inalienables rutas que les marcan sus fines, tienen que coincidir necesariamente en el campo de esos grandes problemas sociales que hoy agitan al mundo para prestarse mutua ayuda ${ }^{64}$.

Y con ese propósito... "hemos procurado, incorporando a nuestra legislación [...] los principios universalmente aceptados y formulados muy claramente por la Santa Sede”65. Anteriormente, en el transcurso de la Guerra Civil, Franco había afirmado que: "Nuestro Estado ha de ser un Estado católico en lo social y en lo espiritual; porque

61. Véase Pablo MARTín DE SANTA OLALlA, De la victoria al Concordato: las relaciones Iglesia-Estado durante el "primer franquismo" (1939-1953), Barcelona, Laertes, 2003. Para una visión de conjunto de la evolución de la organización y acciones de los católicos en España en el primer tercio del siglo XX, Feliciano MonTero GARCÍA, El Movimiento Católico en España, 1889-1936, Alcalá de Henares, Editorial Universidad de Alcalá, 2017; del mismo autor, un ensayo historiográfico: "La historia de la Iglesia y del catolicismo español en el siglo XX. Apunte historiográfico”, Ayer, 51 (2003), pp. 265-282.

62. Francisco FrAnCO, “La Labor Social del Nuevo Estado”, Revista de Trabajo, 6 (junio 1949), p. 567.

63. Franco, “En la Clausura del Congreso Apologética” [sic], Franco ha Dicho, vol. 3, p. 38.

64. José Antonio GIRÓn, “Discurso en la clausura de la Semana Social de Málaga”, Revista de Trabajo, 5 (mayo 1949), p. 445.

65. GIRÓN, Quince Años, p. 14. 
Católica, ha sido, es y será la verdadera España” ${ }^{66}$. En realidad, las relaciones del régimen español con el Vaticano se caracterizaron por la confrontación entre dos fuerzas contradictorias, es decir, una evidente recuperación de patrimonio e influencia de la Iglesia sobre la población con el consentimiento del Estado, pero de la Santa Sede venía una desconfianza en cuanto al proclamado clamor católico de Franco, desconfianza que crecía a medida que se afirmaba la desventaja del lado fascista de los regímenes europeos ${ }^{67}$.

A mediados de la década de 1950, Franco avisa del logro de la consecución del objetivo (uno más en el entendimiento del régimen) arriba mencionado, cuando afirma: "Hemos querido y creado un Estado católico unido a la Iglesia por un Concordato que

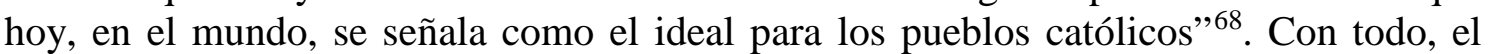
Concordato de 1953 no sería renovado en España ${ }^{69}$ (aunque fuera, "en esencia, la plasmación jurídica del espíritu de nacionalcatolicismo, aquella ideología que afirmaba la consustancialidad entre Religión Católica y nación española"70), lo que podría suponer un alejamiento del régimen relativamente a la visión católica, al avistarse los años 1960, y con ellos una nueva fase del Franquismo y de su política social.

Sin embargo, si se entiende el yugo que el Estado franquista coloca sobre la estructura católica española, se esclarece la naturaleza de las relaciones entre EstadoIglesia: "A la Iglesia corresponde y toca hacer lo que requiera el orden espiritual y de la fe, que nosotros facilitamos y estimulamos"71. Se comprueba aquí, y por una vez más, una nueva sintonía evidente entre los dictadores ibéricos respecto al papel de la Iglesia en cada una de las sociedades. Salazar, cercano a la estructura eclesiástica portuguesa, tal vez más que su homólogo español, afirma claramente y sin rodeos:

\begin{abstract}
Nós tiramos da experiência esta dupla lição: melhor se rege a Igreja a si própria, em harmonia com as suas necessidades e fins, do que pode dirigi-la o Estado através da sua burocracia; melhor se defende e se robustece o Estado a definir e realizar o interesse nacional nos domínios que lhe são próprios, do que pedindo emprestada à
\end{abstract}

66 Francisco Franco (noviembre 1937), “Declaraciones al Corresponsal de la N. G. W. News Service”, Pensamiento Católico, Madrid, Centro de Estudios Sindicales, 1958, p. 14. La realidad es que la Iglesia representó, en aquel contexto cronológico-político, un gran atractivo para muchos: "El catolicismo [...] sirvió de base común para los diversos integrantes de la coalición vencedora. Resultaba muy útil para todos: para los agradecidos a un régimen que les había devuelto todo y para los que sencillamente bastante tenían con subsistir, algo que en tiempos de silencio, muerte y hambre no era poco" (CASANOVA, La Iglesia de Franco, p. 20).

67. Pablo Martín DE SANTA Olalla, “La transición democrática de la Iglesia católica española” (notas), Estudios Eclesiásticos, vol. 75, n. ${ }^{\circ} 295$ (2000), p. 727.

68. FrAnCO, “Mensaje a los Españoles con motivo del Año Nuevo”, (31-12-1956), Discursos y Mensajes del Jefe del Estado. 1955-1959, Madrid, Publicaciones Españolas, 1960, p. 267. En lo que entendemos como una casi anuencia del carácter autoritario-fascista del régimen, FRANCO proclama y engrandece su Estado no laico: "Podrán tacharnos de autoritarios o de lo que sea, pero no podrán discutirnos nunca que los principios de la ley católica, de la confesionalidad del Estado” (18-7-1960, “Discurso en el acto de clausura de las Jornadas Técnicas Sociales, Barcelona”, Discursos y Mensajes del Jefe del Estado (19601963), Madrid, Publicaciones Españolas, 1964, p. 73). Véase sobre la temática específica, Feliciano Montero y Joseba Louzao VILlar (eds.), Catolicismo y franquismo en la España de los años cincuenta. Autocríticas y convergencias, Granada, Comares, 2016.

69. MARTín DE SANTA Olalla, “De la dictadura a la democracia”, p. 424.

70. Pablo Martín de SANTa Olalla SAludes, “El Concordato de 1953 y la España católica”, Estudios Eclesiásticos, vol. 91, n. ${ }^{\circ} 356$ (2016), p. 175

71. Franco, “Palabras en Madrid” (14-04-1944), Pensamiento Católico, p. 69. 
Igreja força política que Ihe falte. Digamos por outras palavras: o Estado vai abster-se de fazer política com a Igreja, na certeza de que a Igreja se abstém de fazer política com o Estado. Isto pode ser e deve ser assim ${ }^{72}$.

Retomando el discurso franquista, es pertinente notar una nueva contradicción, la identificación de un doble discurso que Franco practica durante años: el discurso político cuyos destinatarios eran endógenos, es decir españoles, no coincidía necesariamente con el que se propalaba al exterior. A pesar de la declaración arriba citada, que delimita la esfera en la cual la Iglesia debería funcionar, la colaboración entre el Estado y la Iglesia es descrita como existente (y eso no lo discutimos), pero también en pie de igualdad, o por lo menos de colaboración equitativa, lo que no corresponderá a la realidad:

En un país católico, como el nuestro, todos cooperan a la obra social: la Iglesia, con su alta inspiración y magisterio, y el Estado y sus autoridades delegadas, con la directa responsabilidad en su ejecución ${ }^{73}$.

Más allá de la anunciada separación de influencias, lo cierto es que la promiscuidad entre estas dos esferas de poder está presente. Casanova presenta una visión afilada del papel estatal que la Iglesia de Franco cumple:

La Iglesia implicada, y tomando parte hasta mancharse, en un sistema estatal de represión. No se conoce otro régimen autoritario, fascista o no, en el siglo XX, y los ha habido de diferentes colores e intensidad, en el que la Iglesia asumiera una responsabilidad política y policial tan diáfana en el control social de los ciudadanos. Ni la Iglesia protestante en la Alemania nazi, ni la católica en la Italia fascista ${ }^{74}$.

Esta estrecha conexión está igualmente patentada por el hecho de al Jefe del Estado español le estaba reservado el derecho de presentar oficialmente al candidato de su elección para cada sede episcopal, proceso que a partir de 1941 pasa a ser negociado con la Nunciatura: el Gobierno presentaba seis posibles nombres de candidatos para determinado lugar, la seisena, de los cuales el Papa seleccionaría tres, la terna, y le tocaba a Franco la decisión final, oficializada enseguida por el Papado.

En 1945, ante el colapso del Eje, el Estado franquista se coloca de nuevo bajo el manto protector y legitimador de la Iglesia, al afirmar que

no es un Estado caprichoso el que salió de nuestra Cruzada, sino un Estado católico, eminentemente social [...] Nuestras leyes y disposiciones están impregnadas del mismo espíritu católico que animó España en las grandes empresas de su Historia ${ }^{75}$.

Incluso porque (completa otro discurso), "nuestra obra seria incompleta si no contáramos con el espíritu; y por eso, sobre el pan y la justicia, ha puesto el Movimiento

72. SALAZAR, "Discurso na Assembleia Nacional durante a aprovação da Concordata assinada com o Vaticano”, Discursos e Notas Políticas (25-5-1940), vol. III, pp. 238-239; cursiva en el original. El Concordato portugués, de 7-5-1940 (el proceso diplomático habia sido iniciado en 1937) "confere um amplo conjunto de privilégios à Igreja. Desde logo porque a República Portuguesa lhe reconhece personalidade jurídica e lhe garante o livre exercício da sua autoridade, organização e culto. [...] E ainda a isenção da Igreja de contribuições dos templos e estabelecimentos destinados à formação do clero” (Maria Inácia REzOLA, “A Igreja Católica portuguesa e a consolidação do salazarismo”, en PINTO y MARTinHo (orgs.), O Corporativismo em Português, pp. 269 y 270.

73. FrANCO, "Declaraciones al corresponsal en Madrid del Diario francés 'Le Figaro”” (16-12-1963), Discursos y Mensajes, p. 602.

74. Casanova, La Iglesia de Franco, p. 292.

75. Francisco FranCO, “En la Clausura del III Consejo Nacional Sindical”, Revista de Trabajo, 2 (febrero 1945), p. 142. 
el reinado de la Cruz"76. Efectivamente, la postura paternalista del Franquismo en cuanto a lo social encuentra respaldo en la acción caritativa de la Iglesia:

Es necesaria la caridad, que dé incluso aquello a que no se tiene derecho, y esto sólo puede existir en una justicia presidida por un concepto espiritual de la vida concebida bajo el imperio del Evangelio ${ }^{77}$.

\section{Consideraciones finales}

Los regímenes ibéricos que se establecieron en la década de 1930 desarrollaron políticas sociales, particularmente en los campos de la asistencia y previsión sociales, que les fueron especialmente útiles como instrumentos de convencimiento, buscando un consenso dentro de la sociedad y con el objetivo de lograr su aceptación. Además, a través de una retórica poderosa, los intervinientes transformaron estas políticas en eficaces herramientas de propaganda de su obra nacional, que fue presentada como innovadora y plena de preocupación social, sometida a un designio moralmente superior. Así, la estrategia política de las dictaduras implicó a un poderoso y antiguo aliado, la Iglesia Católica, que al ser rescatada del anticlericalismo republicano de izquierda franqueó, a la vez, las puertas de las sociedades al control del Nuevo Estado y del Estado Novo, y actuó frecuentemente como la voz de los regímenes. La identificación de las políticas sociales de los regímenes con los valores tradicionales de la Iglesia ha facilitado la legitimación del poder político. En España, el régimen hace crecer las referencias y vinculación de su discurso al catolicismo, pues a medida que la Segunda Guerra Mundial evoluciona desfavorablemente, el franquismo tuvo que actualizar sus definiciones ${ }^{78}$. Por lo tanto, al régimen le quedaban solamente dos cartas a partir de 1945, el catolicismo y el anticomunismo, con una creciente relevancia del primero. Esta circunstancia la encontramos ejemplificada de la misma manera en el caso portugués... "Sem dúvida, o estatismo, o comunismo, o liberalismo têm razão de ver no corporativismo português um inimigo mortal" ${ }^{\prime 2}$... en que el Estado Novo solamente añade a sus pilares de sustentación ideológica una dimensión colonial, que asume una gran envergadura cuando comparada con la española. En definitiva, Portugal y España compartieron, sobre todo, la utilización de los valores de la doctrina social de la Iglesia,

76. Franco, “En Badajoz” (18-12-1945), Pensamiento Político de un General: Franco, vol. III, p. 810.

77. Francisco Franco, Discurso pronunciado por S. E. el Jefe del Estado ante las Cortes españolas al inaugurar su segunda legislatura (14-5-1946), Madrid, Publicaciones Españolas, 1946, p. 32.

78. “Em Espanha a hierarquia católica tinha os meios e o apoio político [...] na concordata de 1953, Franco concedeu à Igreja, não só isenção de impostos e a ausência de qualquer interferência do Estado, mas também o direito de requerer a censura de qualquer texto ou discurso a que objectasse. Em contrapartida, a hierarquia eclesiástica mantinha e reforçava a interdependência conservadora da religião com a identidade nacional. [...] Como Franco precisava do catolicismo ainda mais do que a Igreja precisava de Franco -de que outra forma se manteriam no pós-guerra as ténues ligações da Espanha com a comunidade internacional e o 'Ocidente'?-, concedeu-lhe, de facto, um âmbito ilimitado para recriar na Espanha moderna o espírito de 'cruzada' do ancien régime” (Tony JuDT, Pós-Guerra. História da Europa desde 1945, ed. de Lisboa, Edições 70, 2009, pp. 271-272).

79. SALAZAR, "Discurso na Emissora Nacional” (25-6-1942), Discursos e Notas Políticas, vol. III, pp. 328-329. El dictador portugués afirmarçia años más tarde y de forma inequívoca que, "o comunismo é essencialmente inconciliável com os princípios da chamada civilização ocidental e nenhuma fórmula de entendimento ou compromisso sério se pode conseguir com ele” ("Em Braga, por ocasião da inauguração do estádio municipal”, 28-5-1950), ibídem, vol. IV, p. 473). 
vastamente incorporados en el discurso social de los regímenes, aunque adornados por una musculatura fascistizada que se fue matizando a lo largo de las décadas. 